\title{
BLOCH - PROCURA POR NÓS MESMOS NO UTÓPICO. O CAMINHO DO ESPÍRITO DA UTOPIA AO CONJUNTO DA OBRA ${ }^{12}$
}

\author{
Wolfdietrich Schmied-Kowarzik ${ }^{3}$
}

\begin{abstract}
Resumo $^{4}$ :
Espírito da utopia, de Ernst Bloch, foi escrito durante os anos da I Guerra Mundial, durante sua emigração na Suíça, e publicado em 1918. Neste livro, Bloch procura contrapor à loucura da guerra a pergunta pelo sentido, a qual, quando existencialmente entendida, há de conduzir a um "autoencontro" conosco mesmos. Bloch concentrase especialmente em três círculos temáticos: o autoencontro nas artes plásticas, na música e na "questão inconstrutível" para nós mesmos, na filosofia. O movimento dialético interno disso Bloch resume, como lema de seu filosofar, em três frases: "Eu sou. Mas eu não me tenho. Com isso nós primeiramente seremos". Já no "com isso nós primeiramente seremos", fica claro que Bloch não compreende seu existencialismo de modo individualista, pois o autoencontro filosófico do ser humano somente pode ser exitoso em uma sociedade humanosocial. Portanto, o compromisso com uma sociedade socialista e ecológica não deveria ser degenerado a algo técnico-científico, mas, justamente em relação ao socialismo a ser construído, aquela questão com a qual a filosofia já desde sempre se ocupa deve ser posta da forma ainda mais radical. Nosso engajamento por uma convivência mais humana entre nós e por uma interação responsável com a natureza deve ser capaz de resistir até mesmo diante de um possível fim da nossa história terrena. É nisso que culmina o dramático capítulo final "Karl Marx, a morte e o apocalipse" e nisso consiste o persistente desafio do Espírito da utopia para nós hoje.
\end{abstract}

Palavras-chave: Autoencontro. Virada 'proflexiva'. Marxismo. Utopia.

\section{SUCHE NACH UNS SELBST IM UTOPISCHE. DER WEG VON GEIST DER UTOPIE ZUM GESAMTWERK}

\section{Zusammenfassung:}

Ernst Blochs Geist der Utopie wurde in den Jahren des Ersten Weltkriegs in der Emigration in der Schweiz geschrieben und erschien 1918. In diesem Buch versucht Bloch gegen den Wahnsinn des Krieges die Sinnfrage zu stellen, die wenn sie existentiell gemeint ist, sich zu einer „Selbstbegegnung“ mit uns zu führen hat. Auf drei Themenkreise konzentriert sich Bloch dabei ganz besonders: die Selbstbegegnung in der bildende Kunst, in der Musik und in der „unkonstruierbaren Frage“ nach uns selbst in der Philosophie. Deren innere dialektische Bewegung Bloch als Motto seines Philosophierens in dem Dreisatz zusammenfasst: „Ich bin. Aber ich habe mich nicht. Darum werden wir erst." Schon im „darum werden wir erst" wird deutlich, dass Bloch seinen Existentialismus nicht individualistisch versteht, denn die philosophische Selbstbegegnung des Menschen kann nur in einer sozial-humanen Gesellschaft gelingen. Daher darf der Einsatz für eine sozialistische und ökologische Gesellschaft nicht zu einer wissenschaftlich-technischen Angelegenheit verkommen, sondern die Sinnfrage, die die Philosophie seit je her umtreibt, muss gerade für den uns aufgegebenen Sozialismus in radikalster Form gestellt werden. Unser Einsatz für ein humaneres Zusammenleben der Menschen und einen verantwortlichen Umgang des Menschen mit der Natur, muss auch angesichts eines möglichen Endes unserer irdischen Geschichte Bestand

1 Título original: Suche nach uns selbst im Utopische. Der Weg von Geist der Utopie zum Gesamtwerk. Publicado em: Schmied-Kowarzik, Wolfdietrich. Denken aus geschichtlicher Verantwortung. Wegbahnungen zur praktischen Philosophie. Würzburg: Königshausen/Neumann, 1999, p. 210-232.

2 Rosalvo Schütz traduziu este artigo. Schütz é docente de Filosofia na Universidade Estadual do Oeste do Paraná - UNIOESTE. Bolsista de produtividade do CNPq. A tradução é um dos resultados do pós-doutorado na Universidade Católica do Rio Grande do Sul (PUCRS) entre 2019 e 2020.

3 Professor emérito de Filosofia da Universidade de Kassel (Alemanha), atualmente residente em Viena/Áustria. Vários trabalhos seus foram traduzidos no Brasil, sendo um dos mais recentes o livro A relação dialética do homem com a natureza. Estudos histórico-filosóficos sobre o problema da natureza em Karl Marx, pela EDUNIOESTE. Atualmente vem lançando diversos estudos especialmente sobre questões ambientais e filosofia intercultural.

4 Resumo elaborado pelo autor especialmente para a presente versão brasileira do texto. (Nota do tradutor). 
haben können. Darin gipfelt das dramatische Schlusskapitel „Karl Marx, der Tod und die Apokalypse“ und darin liegt auch die bleibende Herausforderung von Blochs Geist der Utopie für uns heute.

Stichwörter: Selbstbegegnung; 'proflexive’ Wendung; Marxismus; Utopie.

\section{Esclarecimento prévio}

$\mathrm{Na}$ tentativa de apresentar a obra de Ernst Bloch gostaria de me concentrar na primeiríssima obra, Espírito da utopia (1918), uma vez que nela estão reunidos em germe os motivos do seu filosofar, os quais foram perseguidos separadamente em sua obra tardia. Apenas em um olhar perspectivo eu irei, depois disso, esboçar o fio condutor de suas obras sistemáticas posteriores.

Quem intenta apresentar de forma introdutória a filosofia de Ernst Bloch e, ainda por cima, desde sua obra precoce Espírito da utopia, se vê primeiramente confrontado com a pergunta se de fato Ernst Bloch é um filósofo - ou mesmo um grande; e, se sim, de que tipo de filosofia se trata. Evidentemente teremos de imediatamente "perguntar de volta" sobre quem é que nos obriga ao esclarecimento de tal pergunta prévia. Se ela vier do campo da "filosofia analítica”, nós a devemos ignorar de modo convicto, pois, segundo os critérios desta, toda grande filosofia alemã - de Hegel até Heidegger - sucumbe à suspeita de falta de sentido e, certamente, Bloch é um autor e pensador genuinamente alemão. Mas também em nossa tradição existem estruturas periféricas cujo ainda-pertencimento à filosofia é permanentemente questionado. O exemplo mais famoso é o de Friedrich Nietzsche. É Nietzsche um filósofo ou é ele um genial escritor crítico-cultural? Semelhantes questões de classificação também foram feitas a Bloch. Questões essas que não provêm de um lugar qualquer, mas, dentre outros, de dois amigos bem familiares de Ernst Bloch: Georg Lukács e Theodor W. Adorno.

Perguntado se considera Ernst Bloch, seu amigo de juventude, um marxista, Georg Lukács respondeu que Ernst Bloch não era um marxista mas um socialista de esquerda correto, por quem, por isso, tinha uma grande consideração. E que ele também não era um filósofo, mas - citando-o literalmente - "O outro lado é que eu considero Ernst Bloch sobretudo um dos escritores mais instigantes que conheço. Se me é permitido dizer: é um estilo marcante, uma mistura da Caixinha dos Tesouros de Hebel e a Fenomenologia de Hegel. E na história da prosa alemã isso é algo bem peculiar [...]” (Lukács apud Bloch, 1985, p. 374).

Da mesma forma, seu amigo próximo (Dutzfreund) Teddy, Theodor W. Adorno, considera Ernst Bloch um grande escritor expressionista de pensamentos profundos. As poucas

\begin{tabular}{|c|c|c|c|c|}
\hline Q Povista Dialectus & Ano 10 & n. 21 & Janeiro - Abril 2021 & p. $271-295$ \\
\hline
\end{tabular}


observações por escrito em relação a Bloch encontram-se nas Notas sobre literatura. Como pensador filosófico, no entanto, ele não levou muito a sério seu amigo Ernst ${ }^{5}$.

Sigamos, no entanto, um passo adiante em outra direção. No novo movimento do pensamento pós-moderno, que, desde a França, vem se ampliando fortemente também entre nós, toda filosofia argumentativa é, conhecidamente, desconstruída literariamente, atacada (Verworfen) e tida como compromissada com a incurável racionalidade ocidental. Notadamente, daí são excluídos o movimento romântico (Novalis), Friedrich Nietzsche e Ernst Bloch e celebrados como fundadores do pensamento pós-moderno.

Eu me refiro a tudo isso para mostrar que em Ernst Bloch nós temos um caso muito raro de um pensador, no campo da língua alemã, que também é um escritor (Schriftsteller). O gênero literário no qual Ernst Bloch atingiu a maestria literária é - algo também raro na Alemanha - o ensaio. (Pensemos em Michel de Montaigne, Thomas de Quincey, Jorge Luiz Borges como mestres do ensaio pensante). Em Bloch trata-se, tanto de ensaios quase preenchidos de aforismos, assim, por exemplo, na sua significativa obra literária Vestígios [Spuren], quanto do ensaio amplo e sistematicamente desdobrado, como, por exemplo, na sua principal obra filosófica Princípio Esperança, cujos três volumes poderiam ser tomados como um gigantesco ensaio, constituído da junção de ensaios sobre o tema "Sonhos de uma vida melhor".

Mas uma tal homenagem a Ernst Bloch como escritor não deve perder de vista que, nas suas obras, se trata de expressões filosóficas, isto é, da apreensão genérica de nosso serhumanidade e não, como em prosa e verso, da apresentação do agora (des je) concreto. Mesmo assim, aqui é preciso fazer uma diferenciação bem exata: há outros filósofos que se esforçaram por uma densa linguagem literária, como Heidegger e Adorno, mas, para eles - por mais diferentemente que isso aconteça -, trata-se primeiramente de encontrar palavras e frases apropriadas para o pensamento filosófico. Algo bem diferente acontece no ensaio de Bloch: aqui não é o pensamento que dita a estruturação linguística; muito antes, é a estrutura linguística de uma imagem, de uma vivência, uma história que se antepõe e é somente por meio delas que pode emergir (zum Vorschein) o pensamento filosófico. Dois exemplos retirados dos Vestígios [Spuren] certamente esclarecerão isso. Por um lado, a história aforística A pobre [Die Arme] e, por outro lado, o método ensaístico apresentado pelo próprio Bloch em O Notar [Das Merke]:

5 Aqui há um jogo de palavras que se perde na tradução: Ernst [que significa sério] não foi muito "levado a sério (ernstgenommen)!". 


\begin{abstract}
A pobre.
O que eles fazem? - eu pergunto. Eles poupam luz, diz a pobre mulher. Ela está sentada na cozinha escura, há tempo. Isso, em todo caso, era mais fácil que poupar comida. Como não há o suficiente para todos, é a vez dos pobres. Eles estão a serviço dos seus senhores, mesmo quando estão descansando e abandonados (Bloch, 1977f, p. 16).
\end{abstract}

O Notar.

Cada vez mais surge, entre nós, algo ao lado. Fica-se atento justamente às pequenas coisas, e se as segue. O que é leve e raro, muitas vezes, é o que conduz para mais longe. Se escuta uma história como a da [pobre]. Repentinamente, também é bom pensar fabulando pois tanta coisa não consegue lidar consigo mesmo quando acontece, mesmo lá onde é contado de forma bonita. Ademais, muito estranhamente, aí dentro age algo mais [...]. Histórias desse tipo não apenas são contadas, mas também se conta o que aí dentro foi espancado ou se escuta atentamente: o que andou aí. Enquanto evento surge aí um notar [...], pequenos incidentes são tomados como vestígios e exemplos [...]. Algumas coisas só se deixam apreender em tais histórias, não num estilo mais elevado ou alargado, ou então não assim. Dependendo de como algumas dessas coisas são percebidas, se tenta continuar a notar ou a indicar. Amorosamente, notando no conto, intencionando o contado no notar. São uns e outros pequenos traços oriundos da vida, os quais a gente não esqueceu [...]. É uma leitura de vestígios para lá e para cá, em recortes que apenas dividem a moldura, pois, por fim, tudo que vem ao nosso encontro e é percebido, é o mesmo (Bloch, 1977f, p. 16 Ss.).

Essa forma de se aproximar da generalidade dos problemas concretos por meio de

contos (erzählend) perpassa toda a obra de Bloch, e não apenas seus textos dominantemente literários, mas também seus trabalhos sistemáticos, chegando até mesmo a seu grande acerto de contas com Hegel em Sujeito-Objeto [Subjekt-Objekt]. Seu pensamento gira em torno de questões que abrem problemas e não de respostas que deem segurança ao conhecimento.

Aqui, certamente, se encontra a força de Bloch como pensador filosófico, pois em filosofia se trata - é o que eu acho - muito mais da abertura de novos horizontes de problemas e da irrupção de novas dimensões de questionamentos do que de uma fixação racional de conceitos e deduções de pensamentos, os quais antes distorcem problemas e matam questões, ao invés de deixá-las viver em nós.

No entanto, também aí se encontra o limite da filosofia blochiana, pois, assim como ele entende muito bem como adentrar nas profundas questões metafísicas, tanto também falha e se nega à argumentação filosófica estrita. Bloch dá pouca importância à fundamentação filosófica dos problemas e às demonstrações; meditativamente/ensimesmadamente (grübeld) e na forma de contos (erzählend) ele tenta avançar mais profundamente do que aquelas, pressentir questões a fim de fazê-las emergir (zum Vorschein bringen). Daí seu pensamento permanecer indicação e afirmação.

\begin{tabular}{|l|l|l|l|l|}
\hline Qovista Dialectus & Ano 10 & n. 21 & Janeiro - Abril 2021 & p. $271-295$ \\
\hline
\end{tabular}


Tudo isso, no entanto, compõe apenas algumas das dificuldades para se explicitar a filosofia de Ernst Bloch em alguns curtos esboços. Aqui eu gostaria de fazer isso, desde uma de suas primeiras obras, deslocando para o centro o leitmotiv do seu pensamento. Nessa tarefa, pretendo deixar o máximo possível a palavra ao próprio Bloch, mas, simultaneamente, delimitar, esclarecendo e comentando, os contornos do fio condutor de seu pensamento. Pretendo, também, indicar, perspectivamente, a influência desse pensamento no conjunto da sua obra e concluir com algumas observações críticas.

\section{I - Estruturas do encontro consigo mesmo}

Espírito da utopia tem sido chamado de uma obra expressionista e o próprio pensamento de Bloch tem sido atribuído ao expressionismo. Isso certamente está correto no que diz respeito ao estilo de Espírito da utopia e, também, em relação a algumas outras obras; no entanto, do ponto de vista histórico-filosófico, certamente essa não é uma classificação com muito sentido. Ernst Bloch pertence muito antes ao campo do pensamento - até hoje ainda muito pouco pesquisado - do cedo-existencialismo (frühexistentialistischen Denkens), que surgiu a partir dos impactos da loucura da I Guerra Mundial - de modo semelhante como o existencialismo mais tardio de Sartre e Camus emerge dos estremecimentos causados a partir da segunda catástrofe europeia. O pacifista convicto Ernst Bloch escreve Espírito da utopia durante os anos de guerra de 1915 até 1917. Porém, não se trata de um livro que faça um acerto de contas com os horrores da primeira catástrofe europeia desse século. Sim, ela está impressionantemente sobreposta e afastada da carnificina dos campos de batalha, dos estrondosos combates de artilharia e do sufocante gás mortal. Espírito da utopia está direcionado a uma única questão: o encontro existencial consigo mesmo, o encontro com o ponto de partida desde onde se possa começar de novo e desde onde seja possível fazer irromper as grandes esperanças da humanidade, quando a loucura dominante uma vez tenha passado. É assim que Bloch, em 1918, após o sangramento da guerra, apresenta a "intenção” do livro:

Como então?

Isso é suficiente. Agora temos de começar. A vida foi colocada em nossas mãos. Por si mesma, ela há muito tempo já se tornou vazia. Ela oscila de um lado para o outro, destituída de sentido, mas nós estamos firmes e, desse modo, queremos nos tornar para ela a sua iniciativa e os seus objetivos.

$\mathrm{O}$ que aconteceu agora em breve será esquecido. Ficou no ar apenas uma recordação vazia, lúgubre. Em favor de quem se advogou? Os preguiçosos, os miseráveis, os aproveitadores, foi em favor deles que se advogou. $\mathrm{O}$ que era jovem teve de ser descartado [...]. Os dignos de compaixão, todavia, foram salvos e estão sentados no acolhedor cômodo aquecido. [...] E apenas isso é importante. [...] Temos saudade e conhecimento limitado, mas pouca ação e, o que explica a sua ausência, nenhuma 
amplitude, nenhuma perspectiva, nenhuma conclusão, nenhum limiar interno supostamente ultrapassado, nenhum conceito utópico principal. [...] Encontrar esse conceito, encontrar o conceito correto, para isso vale a pena viver, organizar-se, ter tempo, para isso nos movemos, para isso abrimos os caminhos metafísicos constitutivos, chamamos o que não é, divagamos, divagamos dentro de nós e procuramos lá o verdadeiro, o efetivo, onde desaparece o que é meramente factual incipt vit nova (Bloch, $1977 \mathrm{c}$, p. 9) ${ }^{6}$.

No próprio livro, o "encontro consigo mesmo" apreendido existencialmente - como é intitulada a parte principal - está no centro das reflexões: o encontro consigo mesmo por meio das belas artes [bildende Kunst] ("criação do ornamento"), o encontro do ser humano consigo mesmo por meio da música ("filosofia da música”) e, por fim, o encontro filosófico consigo mesmo na "estrutura da questão inconstrutível" [Gestalt der unkonstruierbaren Frage]. A isso então se interliga o capítulo final sobre "Karl Marx, a morte e o apocalipse", o qual abordarei de forma mais exaustiva. Primeiramente, no entanto, buscarei indicar rapidamente e, mediante alguns esclarecimentos e extratos do próprio texto, os contornos basilares da problemática fundamental do ponto de partida existencial no encontro filosófico consigo mesmo.

A fim de entrar em sintonia com a temática da questão absoluta e inconstrutível, que nós somos para nós mesmos, eu gostaria de adiantar uma citação de Schelling, à qual Bloch - semelhante a Heidegger - permanentemente se referiu. Schelling escreve: "Muito distante, portanto, do fato de que o ser humano e o seu agir tornam o mundo compreensível, é ele mesmo o mais incompreensível [...]. Justamente ele, o ser humano, me conduz à última e inquietante pergunta: Por que afinal há algo? Por que não há nada?” (Schelling, 1858, p. 07).

É justamente dessa primeira e última questão que se trata, pois, apesar de ela irromper em nós mesmos, nessa nossa procura por nós mesmos ela acaba abarcando o horizonte de sentido de todo o cosmos e, por fim, ela nunca pode ser respondida de modo conclusivo. $\mathrm{Na}$ segunda edição de Espírito da utopia (1923), Bloch introduz, a fim de dar destaque ao seu pensamento mais básico, mais um subcapítulo: "Sobre a metafísica do nosso obscuro, nãomais-consciente, ainda-não-consciente, inconstrutível problema do nós" (eu cito aqui e adiante a partir dessa segunda edição):

Estou junto a mim mesmo.

6 Cotejado com a segunda edição de Geist der Utopie [Espírito da utopia] (Bloch, 1977d) conforme tradução de Oliver Tolle (Bloch, S/D, p. 02 e 04). Nos trechos inalterados em relação à primeira edição usamos a tradução de Tolle, a quem agradecemos a cedência do texto traduzido do livro no prelo. Agradecimentos também à Ubiratane de Moraes Rodriges que, além de indicar a tradução de Tolle, "garimpou" na versão traduzida para o português, as demais citações de Espírito da utopia, utilizadas no presente texto. (Nota do tradutor)

n. 21

Janeiro - Abril 2021

p. $271-295$ 
Com isso, por fim, há de se começar. [...] Isso é suficientemente pouco e aqui quase tudo vai junto a pique. Mesmo o que é bom, porque o homem repousa indeciso em esteiras e nada adquire cor alguma. Apenas este último aspecto é claro: que pouco somos uns para os outros, que podemos passar pelo outro sem prestar atenção a ele. [...] Claro é somente este último: que nós somos muito pouco um para o outro, que podemos passar sem noção pelo outro [...]. Com isso, parece que o opaco aflige ainda mais profundamente, pois quem sou eu, já que posso criar? Possuo mesmo tanto valor, sou mesmo tão amado? Não posso sentir, o frio interior desce a um nível além da medida. Depois de não descobrirmos nada capaz de satisfazê-lo, de onde mais se originam as minhas possibilidades? [...] Desse modo os homens colapsam em si mesmos, desprovidos de caminho, sem objetivo além do cotidiano. Eles perdem a condição de vigília, de possuírem conteúdo, perdem a sua existência propriamente dita, são privados de seu polo, da abrangência de sua consciência de um objetivo (Bloch, S/D, p. 154).

[Mas], se sob a vida oculta, sob o niilismo dessa modernidade, não se agitasse ao mesmo tempo uma força desconhecida em ética ou fantasia, então, justamente por isso, se imporia inúmero terror e obstáculo no caminho. [...] Apenas esse sonho acordado pensante cria coisas efetivas, ao ouvir profundamente em si mesmo, até que a visão seja alcançada [...]. A vida segue ao nosso redor e não sabe para onde vai, apenas nós mesmos somos ainda alavanca e motor, o sentido exterior hesita e sobretudo o sentido revelado: mas o pensamento novo irrompe finalmente, na aventura completa, no mundo aberto, incompleto, sonhador, nos terremotos e eclipses de satã, em virtude do próprio isolamento (Bloch, S/D, p. 158-159).

Nessas frases estão reunidos os pensamentos fundamentais de toda a obra de Ernst Bloch. Tudo o que Bloch escreveu é a tentativa de apreender mais profundamente e expor de modo mais amplo esse pensamento. Aforisticamente e de modo ainda mais condensado, Bloch expressou esse pensamento fundamental nas seguintes três frases conhecidas e muitas vezes citadas: "Eu sou. Mas eu não me tenho. Com isso nós primeiramente seremos" [Ich bin. Aber ich habe mich nicht. Darum werden wir erst.]. Correlacionados a essas três frases encontramse aqui três complexos de pensamento:

1. Não há outro início para o nosso filosofar, para a nossa procura por sentido por e para nós mesmos, a não ser nesse nosso encontro direto conosco mesmos: "Estou junto a mim mesmo". Admiravelmente nós já sempre nos encontramos nessa evidência própria e existencial. Nela se ancora todo o filosofar, mas:

2. "Mas eu não me tenho" - e ainda mais: Eu jamais conseguirei me apreender completamente nesse "Eu junto a mim mesmo". Eu permaneço para mim uma questão inconstrutível: “Quem sou eu? De onde venho? Para onde vou?”.

Bloch também transcreveu a inconstrutibilidade da questão absoluta, que somos para nós mesmos, na fórmula do “obscuro do instante recém-vivido". Nós vivemos, eu sou, mas justamente essa imediaticidade da vida, do sou, a qual nos carrega, e desde onde tudo emerge, não pode ser apropriada nem pela experiência nem conceitualmente.

\begin{tabular}{|l|l|l|l|l|}
\hline Q ovista Dialectus & Ano 10 & n. 21 & Janeiro - Abril 2021 & p. 271 - 295 \\
\hline
\end{tabular}


Portanto, desde essa vivência forçada do não-ter é possível um duplo movimento de procura por si mesmo. O primeiro se volta reflexivamente ${ }^{7}$ para nós mesmos: Sempre onde nos vivenciamos (erleben) nós já não somos mais o instante vivido (gelebte), mas sim apenas asseguramos, pela lembrança, uma experiência, ou, de forma ainda mais dedutiva, um conceito de nós mesmos, o qual, no entanto, nós não somos e o qual já não consegue apreender o sou, que é aquele obscuro do instante vivido, uma vez que esse já há tempo continua pulsando conosco. Nós nunca somos aquela unidade vivenciável ou compreendida de sujeito e objeto. E mesmo assim nós somos desde a unidade desse sou vivido, do qual nós podemos dizer que nós o somos, mas cujo "o que" nós nunca podemos construir de modo conclusivo. Nós somos ocultados de nós mesmos no obscuro do instante vivido do nosso sou.

Toda filosofia do querer-apreender (begreifen-wollende) é a tentativa necessariamente frustrada de capturar reflexivamente, pelo pensamento, o obscuro do instante vivido, de assegurar, por meio de um conceito, aquele sou, o qual nós, vívida e pulsantemente, somos. Entretanto, essas tentativas, que querem nos reconstruir conceitualmente, só podem dar errado, pois que lhes escapa justamente aquilo que tentam apreender: o pulsante e vivido sou (Bin) do nosso existir.

Porém, de um modo totalmente diferente, mesmo assim, ele repentinamente está aí: um instante, um chamado, numa alegria que traz felicidade ou mesmo uma dor profunda que, como um raio, adentram até o mais interno do instante vivido. Em palavras muito poéticas que lembram muito as palavras de Marcel Proust surgidas na mesma época no seu Em busca do tempo perdido -, Bloch descreve esse acontecimento em nós:

\footnotetext{
Uma gota cai e está aí; uma cabana, uma criança chora, uma velha mulher na cabana, do lado de fora há vento, campina, noite de outono, e o mesmo está novamente ali, de igual maneira; ou lemos como Dimitri Karamasov se espanta no sonho que o camponês diga sempre "pequenino", e suspeitamos que poderia ser encontrado aqui: "a ratazana, que ela cicie o quanto quiser! oh, se ela tivesse apenas uma migalha!", e se sentimos junto a esse pequeno verso vil, da Canção do casamento de Goethe, que nessa direção se encontra o indizível, aquilo que o jovem abandonou quando saiu da montanha, "não esqueça o melhor", teria dito o velho para ele, mas ninguém era capaz ainda de encontrar no conceito algo tão imperceptível, profundamente escondido, espantoso (Bloch, S/D, p. 179).
}

Até aqui, portanto, nós seguimos apenas esse um movimento, a tentativa rememorativa e reflexiva, de nos encontrar através da recorrência (Rückwendung) a nós mesmos. E vimos que justamente aquela filosofia racional, que quer apreender, que tenta

7 O segundo movimento, chamado 'proflexivo', será analisado em seguida, no item 3. (Nota do tradutor).

\begin{tabular}{|c|c|c|c|c|}
\hline Qovista Dialectus & Ano 10 & n. 21 & Janeiro - Abril 2021 & p. $271-295$ \\
\hline
\end{tabular}


realizar esse movimento de retorno reflexivo, é marcada por uma decepção (Vergeblichkeit) fundamental, caso ela mesma não se proponha a avançar rumo à aceitação da questão inconstrutível - a grande filosofia de Platão até Schelling sabia disso. Onde Platão avança para seus últimos e mais altos pensamentos, ele fala por meio de imagens, comparações e mitos, já que aí a racionalidade fracassa. Mas nem imagens, melodias ou mesmo a poesia podem construir a questão absoluta que nós somos, embora consigam nos conduzir até mais perto daquilo que procuramos.

3. Mas tudo isso, como dito, é só um dos movimentos do encontro consigo mesmo, que se volta reflexivamente de volta para o não-mais-consciente. $O$ interesse propriamente dito de Bloch é pelo segundo movimento do ainda-não-consciente: "Com isso nós primeiramente seremos". Aqui se encontra antecipada a descoberta mais originária de Bloch: a ampla virada utópica e esperançosa para o ainda-não do porvir.

\begin{abstract}
Assim, abre-se em todo lugar onde começa uma nova vida, aquele questionar franco, espumar, desocultar, enquanto estado da espera da elevação em geral. [...] Sobretudo nos dias de espera, quando o próprio futuro se mescla ao Agora, à violência da felicidade, do modo mais intenso na música, que do começo ao fim tem como objetivo a nossa existência anímica e quer lhe fornecer a palavra. [...] Sobretudo no próprio trabalho criativo é ultrapassada nitidamente aquela fronteira plena de expressão para o ainda não consciente. Um alvorecer, clarividência, um esforço, escuridão interiores, o estrondo de um gelo que se parte, um despertar, um questionar que se aproxima, um estado e conceito, diante da escuridão do instante vivido, diante do apriorístico inominado que maquina em nós, antes de nós, no ser em existência inteiro em si mesmo, para, por fim, acender a luz aguda e idêntica, para abrir os portões do olhar para si mesmo (Bloch, S/D, p. 177-178).
\end{abstract}

Nessa virada "proflexiva" ("proflexive” Wendung) - como Franz Fischer (1985) mais tarde nominou isso - que ousa avançar para dentro do futuro ainda desconhecido, nós temos chances novas e totalmente diferentes de encontrarmos a nós mesmos. Mas não devemos esquecer que também aqui ainda se trata de encontrar a nós mesmos, de encontrar o nosso próprio sentido. Todo o primeiro empreendimento do olhar retrospectivo tinha algo de distante, limitante em si e, mesmo sendo a tentativa de compreender o que nós constantemente já somos, em todo caso só alcançamos aquilo que desde sempre já fomos. Com a virada proflexiva acontece algo totalmente diferente, ela se abre para os muitos horizontes daquilo que ainda é possível, respira o ar fresco do novo, o novum, ela alcança o utópico.

Mas também aqui a questão absoluta, que nós somos para nós mesmos, se mostra, ao fim e ao cabo, inconstrutível. Entende-se Bloch de modo totalmente falso quando se acha que ele quer, com suas imagens de esperança, com seus sonhos de uma vida melhor, prescrever o nosso futuro no Princípio Esperança: ele nem mesmo nos esboça (ausmalen) - como Adorno

\begin{tabular}{|l|l|l|l|l|}
\hline Qenista Dialectus & Ano 10 & n. 21 & Janeiro - Abril 2021 & p. $271-295$ \\
\hline
\end{tabular}


equivocadamente considera - esse mundo futuro. O futuro é inconstrutível, ele é sobretudo aberto. Em Bloch, se trata de nos estimular a nos encontrarmos a partir do horizonte daquilo que é possível, daquele futuro aberto que nos é dado, de esclarecer o esperançar com o qual já sempre estamos a caminho, para frente. Lá onde nós desperdiçamos a oportunidade de acrescentar um esclarecimento pensante ao horizonte do nosso futuro e ao esperançar, aí somos lançados de volta para aquilo que "já-sempre-foi”, permanecemos nas relações constituídas, as quais nos amarram e que também nos acorrentam futuramente ao que permanece eternamente igual.

Ao encontro do sentido de nós mesmos - assim poderíamos transcrever a ideia fundamental de Bloch -, só chegamos quando nos colocamos o horizonte daquilo que é possível, de um futuro a ser coestruturado com nossa própria participação. Naturalmente, isso cada um só pode para si próprio, ninguém pode querer prescrever horizontes de vida e de ação para outros. Também aqui a questão absoluta, que nós somos para nós mesmos, permanece inconstrutível. Mas, mesmo assim, faz sentido, e até é necessário, que a filosofia assuma esclarecidamente esse horizonte de sentido da vida humana.

Uma última observação ainda seja feita aqui: na expressão que contém as três frases - "Eu sou. Mas eu não me tenho. Com isso nós primeiramente seremos" -, Bloch modifica, aparentemente de modo não fundamentado, o sujeito da frase do "eu" para o "nós". Eu não encontrei nenhuma passagem onde ele esclareça isso de modo explícito, mas ele mantém essa mudança de modo muito consequente. Com isso - assim me parece - algo muito importante vem à tona, e que a gente ainda teria de acompanhar de forma mais aproximada. Lá onde nós antecipamos o futuro, e não se trata aqui apenas da práxis, da práxis ética, mas, fundamentalmente, lá onde o ainda-não se torna um problema, justamente aí somos obrigados a aceitar um "horizonte-nós" (Wir-Horizont). A reflexão nos lança - sobre o eu de cada um - a proflexão (Franz Fischer) abre-se pra o nós como sendo o horizonte de nosso agir:

Apenas nós, sozinhos, nos impelimos para o alto, embrenhamo-nos. Não sabemos o que somos, ainda somos intranquilos e vazios e consideramos que escondemos a nós mesmos. De tal maneira que somos apenas nós, o múltiplo, que estamos dados desde o começo e não o mundo ou Deus. Mas apenas diante do que vem será possível conhecer o que procurávamos ou "éramos", antes de entrar nos movimentos temporais; [...] porque o começo só está terminado de fato com o fim, e não é questionável dizer que ele é enigmático; pois já que somos nós cujo início permanece enigmático, já que desse modo a escuridão tão próxima ao nós do instante vivido contém sempre ainda, com força máxima, o enigma do começo, o enigma da existência do mundo, então isso explica justamente todo esse processo mundano de procurar, de querer solucionar o enigma do esclarecimento de nós e da escuridão, do problema originário que se converte em resposta (Bloch, S/D, p. 209).

\begin{tabular}{|l|l|l|l|l|}
\hline Qovista Dialectus & Ano 10 & n. 21 & Janeiro - Abril 2021 & p. 271 - 295 \\
\hline
\end{tabular}




\section{II. "Karl Marx, a morte e o apocalipse"}

Desde 1918 Karl Marx equivale, para Bloch, à transposição prática do esperançoso "horizonte-nós" para a história, para a efetivação concreta do "pensamento socialista". Marx teria superado aquelas más utopias limitadas a apenas esboçar um mundo melhor e teria, desse modo, indicado o caminho concreto-prático a ser tomado, pelo qual nós haveremos de passar a fim de conseguir uma renovação político-social da sociedade. Assim Bloch escreve na segunda edição da versão ampliada e tornada mais precisa em Espírito da utopia de 1923:

[...] No fundo, Marx distinguiu o entusiasmo pura e simplesmente falso, abstrato e sem mediação, o mero jacobinismo da planificação socialista. [...] Para ser prático, para ajudar o horizonte construtivo da vida cotidiana e conduzi-la a um bom termo, para ser político-social, ela se encontra fortemente próxima da certeza e de uma missão inteiramente inscrita e revolucionária da utopia (Bloch, S/D, p. 216).

Por conseguinte, a conduta correta penetra nessas coisas de baixo para cima de modo tão sóbrio quanto possível, de modo a movê-las. Por isso, Marx ensinava de um modo que nunca mais precisou ser tentado e testado como o possível propriamente dito, que a cada momento só se trata do passo seguinte. A esse passo corresponde, no ato revolucionário, ao fato conhecido de que aqui o trabalhador assalariado oprimido, com interesse próprio justificado, se via usado por todos e destinado a cargo importante. [...] E justamente a essa classe, à sua luta de classe à priori economicamente revolucionária, Marx entrega, numa associação grandemente paradoxal, a herança de toda a liberdade, o começo da história mundial depois da pré-história, a primeira revolução total autêntica de todas, o fim de todas as lutas de classes, a libertação do materialismo do interesse de classes em geral (Bloch, S/D, p. 220).

Tanto aqui, quanto em seus escritos tardios, Bloch não aborda Marx e a obra de sua vida, que é a Crítica da economia política, de modo polêmico. Antes a considera como uma obra teoricamente já concluída, para a qual faltaria apenas a transposição revolucionária. Ou seja, que os próximos passos exigiriam apenas a efetivação. A isso eu voltarei mais tarde.

O que, entretanto, Bloch expressa, de modo essencialmente mais claro do que em suas obras posteriores, é a delimitação crítica da obra de Marx, que ele considera carente de organização (ergänzungsbedürftig). Ainda que publicamente, mais tarde, não tenha manifesto abertamente essa sua reserva, - por quais motivos não se sabe - ele dedicou todo a seu trabalho posterior a essa organização:

O que deve ocorrer economicamente, a necessária mudança econômica e institucional, foi determinado por Marx, mas aqui ainda não se atribui a desejada autonomia na ordem social ao novo homem, ao salto, à força do amor e da luz, ato ético ele mesmo. [...] Por isso pode-se dizer que justamente a ênfase aguda em todos os momentos determinantes (economicamente) e nos momentos transcendentes da latência existente, embora ainda envoltos de mistério, aproxima o marxismo de uma Crítica da razão pura, para a qual ainda não foi escrito nenhuma Crítica da razão prática. 
[...] Apenas quem fala não tão somente contra a Terra, mas também contra o céu falsamente revelado, poderá desmistificar o jogo das mentiras burguês e feudal da ideologia de Estado, [...] portanto, obrigação de instalar Marx no cômodo superior, na nova e propriamente dita aventura da vida libertada, no para o quê da sua sociedade, se torna cada vez mais fácil e urgente. Quer dizer: ao conduzir a construção social demasiado restringida novamente na vida amorosa concebida utopicamente por Weitling, Baader, Tolstói, na nova potência das relações humanas de Dostoievsky, no advento da história herética. [...] É assim que deve ser entendida a nova vida, que se tornou tão radical quanto ortodoxa, é assim que se pode vincular a ordem e a sobriedade econômicas e teóricas mais precisas com a mística política e legitimar a partir dela (Bloch, S/D, p. 222-224).

Isso não é apenas um pré-anúncio do próximo capítulo sobre "A autêntica ideologia do reino", mas o esboço programático para toda a obra posterior de Bloch.

$\mathrm{O}$ problema balizador em relação à elevação da perspectiva metafísica - e até mesmo religiosa - do pensamento socialista é o problema da morte, da certeza de que precisaremos falecer:

Eu, contudo, quero ser. O que foi, por fim, deixado para nós? [...] Pois precisamos morrer. [...] Disso se segue que não possuímos nenhum pensamento socialista autêntico. [...] Ainda continuamos esperando, temos nostalgia e saber curto, mas pouco feito e, o que explica a sua falta, nenhuma amplitude, nenhuma perspectiva, nenhum ponto de chegada, nenhum limite interior supostamente transposto. [...] Por fim, sem dúvida, [...] expande-se também a amplitude, o mundo da alma, o diapasão do problema-nós que desmonta e perpassa, a função externa, cósmica da utopia, contraposta à miséria, à morte e ao reino oco da natureza física. É tão somente em nós que brilha essa luz, o último sonho [...] - é tão somente em nós que ainda brilha a luz absoluta [...] o movimento fantástico em direção a ela tem início [...] rumo ao tratamento cósmico do principal conceito utópico (Bloch, S/D, p. 226, com adequações/acréscimos cf. Bloch, 1977d, p. 307-309).

Claro, existe uma indicação de superação socialista, mesmo que momentânea, do medo da morte individual, uma promessa de que nossos engajamentos e lutas sociais continuarão vivos sobre a terra. Todos os mártires e movimentos emancipatórios deram suas vidas com a esperança de que sua intervenção sirva para a vitória do movimento libertário, de que suas ações continuem vivas nas gerações futuras. Mas todas essas esperanças de continuidade viva de nossos feitos são somente de uma abrangência muito curta. Elas mesmas são - como tudo o que é terreno - ameaçadas pelo que é passageiro.

Vale a pena, diante da brevidade deplorável de nossa existência, assumir o trabalho não só para as crianças e a família e a configuração do Estado que já existe atualmente de modo excessivamente antidualista, mas também para qualquer coisa mais ampla que nenhuma alma pode apreender atualmente como um todo, e que consiste conceitual e realisticamente apenas como história, humanidade ou qualquer objetividade que seja? (Bloch S/D, p. 235).

\begin{tabular}{|l|l|l|l|l|}
\hline Qovista Dialectus & Ano 10 & n. 21 & Janeiro - Abril 2021 & p. 271 - 295 \\
\hline
\end{tabular}


Do ponto de vista da morte, relativiza-se até mesmo o pensamento socialista, na medida em que ele está erigido apenas em cima de interesses terrenos. Ou, dito de outra forma: a fim de que, tendo em vista a morte, o pensamento socialista não se disperse, precisamos situálo em outro horizonte de sentido, que possa ser mantido até mesmo frente à problemática da morte.

Para Ernst Bloch, a morte é a contrautopia pura e simples. Ela é o contrapoder de todas as utopias, de todas as constituições de sentido. Ela é o "pior e mais cruel poder [...], o pretendido relâmpago satânico contra tudo o que é humano" (Bloch, 1977d, p. 320). Por meio dela, toda formação de sentido da vida humana é posta em questão; sobretudo se não nos limitamos à morte individual, mas incluímos no pensamento a destruição de culturas ou mesmo a morte de todo o gênero humano.

Aqui Bloch tem a ousadia de enfrentar, de modo meditativo - em contraposição tanto a todos os tabus da racionalidade iluminista quanto à aversão do marxismo em relação à religião e à metafísica -, também as questões da imortalidade da alma, ou seja, da continuidade da existência da alma depois da morte e, principalmente, o pensamento do renascimento (Wiedergeburtsgedanken), com o qual Espírito da utopia claramente simpatiza.

Nisso, entretanto, precisamos tomar cuidado para que não leiamos, nas palavras de Bloch, desacostumados que estamos com esse tipo de pensamento, algo que ele assim não considerava. De modo algum ele afirma ter algum saber em relação ao renascimento da alma. Muito antes ele afirma claramente que nós só temos um conhecimento fático do fim na morte. De modo algum se pode repreender Bloch de que aqui tenha intencionado assumir para si representações ou profissões de fé qualquer, embora ele aproveite e aborde diferentes figuras e expressões da tradição indiana, grega, judaica e cristã.

Para Bloch, se trata permanentemente do encontro conosco mesmos, de acharmos a nós mesmos no horizonte de sentido de nossa vida, em escala mundial e até mesmo cosmohistórica. E justo em relação a esse autoencontro, no horizonte último, é que a morte representa o maior dos desafios, do qual nós não conseguimos dar conta apontando apenas para o nosso saber fático do fim na morte. Com a morte termina tudo? A morte é o fim de todo o sentido? Ou ainda permanece algo de nossa atuação, nosso engajamento ético, preservado para além da morte? (cf. Bloch, 1977d, p. 326).

Aqui expressamente não se trata mais de continuidade das ações terrenas, como a lembrança de uma pessoa por algumas gerações posteriores, nem dos efeitos culturais a longo

\begin{tabular}{|l|l|l|l|l|}
\hline Qevista Dialectus & Ano 10 & n. 21 & Janeiro - Abril 2021 & p. 271 - 295 \\
\hline
\end{tabular}


prazo na história humana, mas, para Bloch, se trata da permanência daquilo que é da alma/espiritual (Seelischen/Geistigen), para além da presença (Dasein) terrena.

Essa não é uma questão espiritualista, mas - como Bloch mais tarde gostava de dizer - uma questão materialista primeira. Justamente, pois, se nós não consideramos a alma/espírito como sendo algo introduzido desde fora, mas a compreendemos como algo que emergiu, como um momento do próprio processo do mundo, então a pergunta pela permanência da alma/espírito depois da morte - depois da morte de cada indivíduo e depois da morte de todo o gênero humano - se coloca de modo impreterivelmente materialista.

Sem um tal questionamento para além da morte, pelo sentido do processo cósmico do mundo, a morte, com sua declaração de falta de sentido, fica com a última palavra. Seria algo equivalente a apagar tudo o que é humano no interior de um processo cósmico, de mundo declaradamente sem sentido. Colocar em questão a possibilidade de um sentido para além da morte tornaria também o estabelecimento de sentido, orientado pelo futuro, algo sem sustentação e objetivo, pois, tendo em vista uma insignificância última da morte, todos os horizontes de justiça, eticidade e humanidade também perdem seu sentido e dignidade.

Para além do problema da morte e de sua contraposição esperançosa por meio da imortalidade da alma e do renascimento - as quais Bloch aborda de modo exaustivo em Espírito da utopia, sem, no entanto, se fixar em uma forma determinada de crença -, podemos encontrar aí também um 'portão de entrada' para a pergunta derradeira da busca por nós mesmos no horizonte futuro de sentido e esperança. Essa é a pergunta pelo apocalipse, da finalidade última do fim do mundo.

Em Espírito da utopia, de 1918 e de 1923, o extermínio do mundo terreno pelo próprio ser humano ainda não está posta. Tem-se em vista apenas a sua morte fisicamente calculável e o esperançar por um horizonte de sentido, um 'tribunal do mundo' (Weltgericht), que seja capaz de superar a morte do mundo e, ante o qual, toda ação humana sobre a terra seja julgada.

"Apocalipse", nesse contexto de problemas, significa duas coisas: por um lado, o fim do mundo em uma catástrofe natural, pela qual a humanidade e o mundo terreno se afundam na morte prematura da terra. Por outro lado, em Bloch, apocalipse também quer dizer - muito judaico-cristãmente - o fim do mundo por sua realização de sentido (Sinnerfüllung).

Silenciosamente o chão começa aqui a oscilar, o qual não parecia mais suficiente para nós. [...] Aqui se pode pressentir um aviso sonoro do fim, um tremular silencioso e distante; [...] e assim, em algum lugar atrás de nós, nos processos subterrâneos e não

\begin{tabular}{|l|l|l|l|l|}
\hline Qevista 2 ialectus & Ano 10 & n. 21 & Janeiro - Abril 2021 & p. $271-295$ \\
\hline
\end{tabular}


mais apenas na entropia, entra em colapso o segundo princípio da termodinâmica, a natureza física. [...] Sabe-se, pode-se saber, por definição, que o mundo, enquanto processo, possui no tempo, assim como um começo, também um fim; o não saber que ele contém, em sua natureza relacional efervescente, não é um estado permanente e precisa encontrar um ponto-limite metacósmico ou em uma vanidade absoluta ou em uma generalidade absoluta [...]. O golpe decisivo ainda não foi dado e [...] torna evidente, na possível morte da substância, na doença da matéria, na natureza desprovida de homens, assustadora, ainda não invocada para si e ainda não florescida, que o ponto de ruptura terrível ainda se encontra aberto para todo envenenamento e detonação, para o ato de explosão propriamente inferior, em princípio inconforme com o dia da maturidade, o ato natural do Apocalipse. [...] Que nós e um Deus sejamos impedidos é o único tribunal sobre nós e sobre Ele, e isso já é suficientemente terrível (Bloch, S/D, p. 247-249).

A decisão sobre se nosso mundo irá findar em um "debalde absoluto" da eliminação de sentido ou em um "absoluto total" do preenchimento de sentido ainda está totalmente aberta. Fundamentalmente também aqui a questão absoluta permanece inconstrutível, pois nós não podemos estabelecer, previamente, pela teoria, no sentido da revelação, o fim do mundo. Mas a orientação de nossa esperança, nossa autoprocura e o encontro de sentido proflexivo precisam permanecer relacionados com a possibilidade de uma completude de sentido positivoapocalíptica, uma vez que é a partir dela que todos os outros horizontes de sentido humano obtêm sua legitimação última.

Bloch não se furta de transcrever essa esperança apocalíptica, capaz de se sobrepor à morte da terra, em metáforas marcadamente cristãs, embora o que intente com isso não seja cristão - ao menos não no sentido confessional dogmático - mas algo profundamente herético, uma religião ateísta. O Cristo somos nós mesmos - como já havia afirmado Meister Eckardt -, nós somos "simultaneamente os andantes e o compasso" e apenas em nós está amadurecendo esse Deus que será mais forte que essa morte última:

Vivemos e não sabemos para quê. Morremos e não sabemos para onde vamos [...]. Todavia, para nós aqui, que sofremos e somos obscuros, permanece a opção de continuar a ter esperança. Se ela permanece suficientemente forte, se ela se torna pura, conserva a si mesma na direção, não permite que ela se torne tola - a esperança não permite que nos tornemos tolos, pois a alma humana abarca tudo, também o que está do outro lado, que ainda não é. Queremos ela tão somente e o pensamento está a seus serviço [...]. Como sua filosofia oscila mais uma vez através do mundo, os portões de Cristo, quer dizer, da adequação da nostalgia dos homens consigo mesmos, se abrem por toda parte, revelando, simultaneamente e em correspondência, o homem secreto, esse presente sempre subentendido, sempre utópico, essa substância idêntica de toda intenção simbólica moral-mítica. [...] Dessa relação funcional entre descarga e espírito, marxismo e religião, unidos na vontade do Reino, fluem conjuntamente todos os tributários em um sistema central final: a alma, o Messias, o Apocalipse - que enquanto tal representa o ato de despertar em sua totalidade - fornece o último impulso para a ação e para o conhecimento, constituindo o a priori de toda política e cultura. [...] Pois somos poderosos; apenas os maus existem por meio do seu Deus, mas os justos - neles Deus existe por meio deles, e nas mãos deles se encontra a santificação do nome, ocorre a nomeação ela mesma de Deus, o qual se move em nós

\begin{tabular}{|c|c|c|c|c|}
\hline Q Rovista Dialectus & Ano 10 & n. 21 & Janeiro - Abril 2021 & p. $271-295$ \\
\hline
\end{tabular}


e impele, portão pressentido, questão mais obscura, interior efusivo, que não é nenhum fato, mas um problema, nas mãos da nossa filosofia que invoca a Deus e na verdade como prece (Bloch, S/D, p. 243-246) ${ }^{8}$.

\section{Esboço do conjunto da obra blochiana}

Asseguremos mais uma vez o leitmotiv do pensamento blochiano: a procura por nós mesmos não se realiza na virada reflexiva em direção àquilo que nós já somos ou fomos. Nós apenas nos encontramos lá onde nos referimos de modo proflexivo para o adiante, para aquilo que ainda não somos, a partir do que, no entanto, projetamos antecipadamente o possível para nós.

Encontrar o sentido de nossa existência, portanto, implica recorrer esperançosamente ao utópico. Essa procura de sentido é algo fundamentalmente inconcluível, pois é levada, por nós mesmos, para horizontes de humanidade sempre mais amplos. Porém, também esses horizontes de plena humanidade, que Bloch vê indicados na obra de Marx, ainda não podem satisfazer nossas questões últimas em relação à procura de sentido, principalmente porque elas podem ser reduzidas a nada pela morte, especialmente pela morte humana. Nosso esperançar, por isso, necessariamente precisa recorrer ao transcendente, onde, porém, Bloch não recorre a um Deus criador, mas direciona sua esperança para o devir inconcluso, ao qual nós mesmos pertencemos e que precisa chegar a si mesmo por meio de nós.

Vale a pena, agora, perseguir esse leitmotiv no conjunto da obra de Bloch. Naturalmente, isso não é possível de ser feito num texto introdutório. Por isso, decidi por apresentar um esboço esquemático das obras sistemáticas de Bloch e então, a partir do mesmo, introduzir alguns esclarecimentos para, assim, estimular a que se siga de perto na própria obra de Bloch o horizonte de questões e interconexões aqui apenas pontualmente indicadas.

Da primeira obra Espírito da utopia se seguem cinco linhas de desenvolvimento, perpassando o Princípio Esperança e seguindo até o Experimentum Mundi, com as quais se pode seguir o desenvolvimento da fundamentação filosófica. Em torno delas deveríamos nos imaginar, de modo tridimensional e relacionados entre si de modo polar, os quatro principais temas real-filosóficos (realphilosophischen Themenschwerpunkte) - no esquema estendidos no nível para baixo e para cima: a filosofia do processo natural, a filosofia da emancipação humana, a estética e a escatologia.

8 Para maiores discussões, confira Schmied-Kowarzik (1993). Wider Barbarei und Apokalypse. In: Bildung, Emanzipation uns Sittlichkeit. [Contra barbárie e apocalipse. In: Educação, emancipação e eticidade].

\begin{tabular}{|l|l|l|l|l|}
\hline Q & Donista \\
\hline
\end{tabular}


a) No Princípio Esperança mais uma vez se interligam todos os principais temas real-filosóficos. "Vontade e natureza", "liberdade e ordem", "estética do pré-aparecer" e "ateísmo e utopia do reino" estão inseridos como partes constitutivas nessa obra filosófica principal de Bloch. A nós, entretanto, aqui nos interessam primeiramente apenas os fundamentos a partir dos quais Bloch descreve, ao dar continuidade ao capítulo sobre "A estrutura da questão inconstrutível" de Espírito da utopia, os contornos de uma "consciência antecipadora".

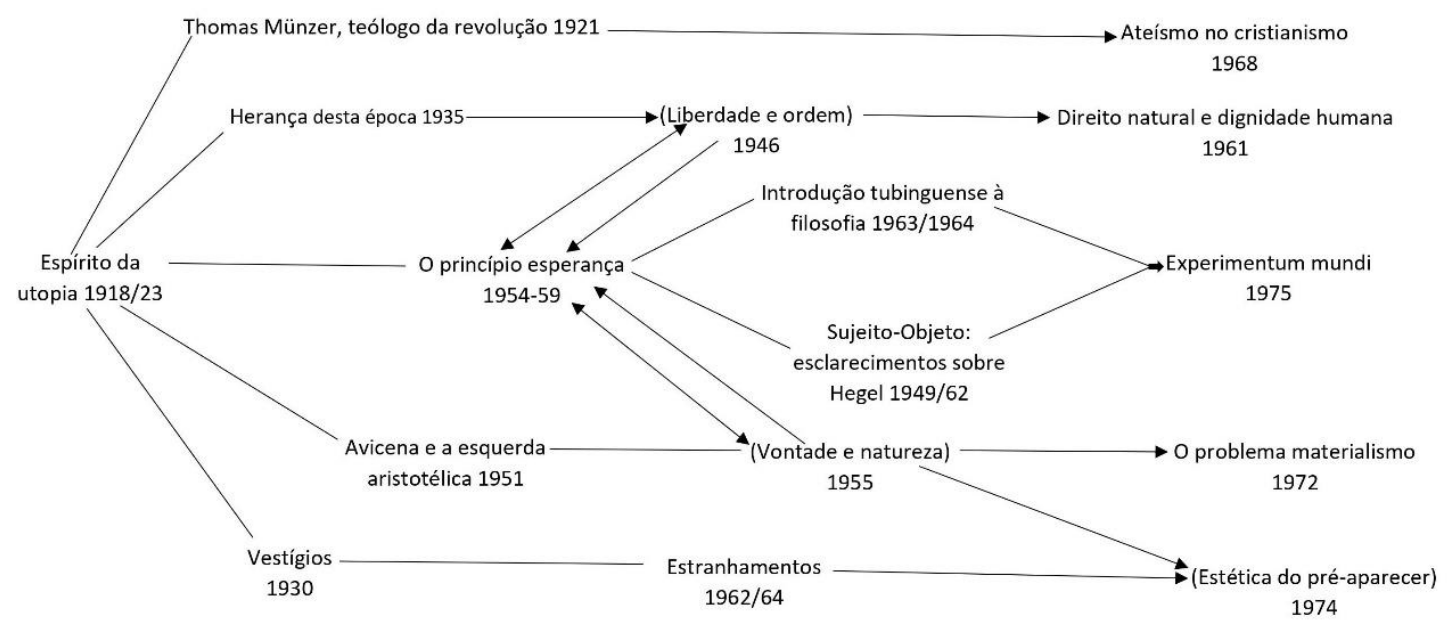

Esquema das obras sistemático-fundantes de Ernst Bloch

Mais uma vez, o ponto de partida é o "sou”, aquele existir in-pré-pensável (das unvordenkliche), que nós já somos e do qual nunca podemos nos apossar, porque, enquanto existente, permanece insondavelmente para além do pensamento, sendo, mesmo assim, aquilo que nos impulsiona e conduz. Não querer fixá-lo - e com isso também não a nós mesmos -, mas sim orientar nosso pensar e agir para frente juntamente como ele, é o que define o caráter fundamental da consciência antecipadora. Nele está o "Princípio Esperança", que não é algo que advém de fora mas também não é algo do qual poderíamos nos esquivar, constituindo antes a orientação fundamental da nossa vida em direção a uma existência humana em completude. "Por isso, a esperança, este afeto expectante contrário à angústia e ao medo, é a mais humana de todas as emoções acessível apenas a seres humanos. Ela tem como referência, ao mesmo tempo, o horizonte mais amplo e claro" (Bloch, 2005, p. 77).

Isso, entretanto, só é possível porque nossa própria existência, ela mesma, pertence à realidade existente, a qual é um processo total e amplamente inconcluso e no interior do qual nós mesmos, com nosso modo de existência e intervenção criativa, estamos inseridos como

\begin{tabular}{|l|l|l|l|l|}
\hline Q ovista Dialectus & Ano 10 & n. 21 & Janeiro - Abril 2021 & p. $271-295$ \\
\hline
\end{tabular}


momento desse processo ainda em aberto. Também o processo total do mundo tem um futuro diante de si que ainda não está fixado, nele ainda estão contidas latências e agem tendências, às quais também a história humana pertence, mas, em seu conjunto, ainda não estão decididas (cf. Bloch, 2005, p. 246).

Com essa consciência antecipadora inserida no processo mundial, vale a pena lançar mais um olhar sobre os desdobramentos mais amplos da fundamentação. E aqui devem ser mencionadas as obras Introdução tübinguense à filosofia, que certamente é uma das autoapresentações mais densas de sua posição de pensamento, assim como seu confronto com Hegel em Sujeito-Objeto. Partindo da dialética do espírito de Hegel, a qual foi um de seus maiores desafios, em Experimentum mundi Bloch finalmente avança rumo à teoria de categorias fundantes de seu próprio pensamento. Teoria essa que, diferente da lógica de Hegel, não pretende se fundamentar a partir de si mesma, mas se compreende como mediação conscientizadora do devir do processo mundial, à qual pertence enquanto tal e a qual ela mesma ajuda a levar adiante.

Isso, portanto, é o experimentum mundi, não apenas como um do mundo mas no mundo, ou seja, o experimento real do próprio mundo [...]. A ele corresponde uma ontologia finitamente enfatizada do ainda-não-ser no ainda-não-consciente, no que ainda não se tornou, ambos presentes nas perspectivas da tendência e da latência, o experimento real das categorias-modos de existir (Daseinsweisen), formas de existir (Daseinsformen) para adiante, como sua matéria (Bloch, 1977b, p. 263).

b) Daqui, portanto, nós podemos nos direcionar à filosofia do processo natural, certamente a parte mais desafiadora de sua obra filosófica. Bloch é provavelmente o único pensador do século 20 que se contrapõe à tendência da filosofia contemporânea de abandonar os esforços de conhecer a natureza exclusivamente às ciências naturais. Assume de forma positiva o projeto de uma filosofia da natureza desde Aristóteles, passando pela "esquerda aristotélica" e a renascença até as gigantescas projeções natural-filosóficas de Schelling e, por fim, também pela Dialética da Natureza de Friedrich Engels, desenvolvendo-o como sendo um problema a ser enfrentado indispensavelmente para o encontro conosco mesmos - algo que expõe sobremaneira em O problema materialismo (Das Materialismusproblem), de 1972 (cf. Schmied-Kowarzik, 2019). Caso queiramos nos compreender inseridos no devir do nosso futuro ainda em aberto, então já precisamos entender também a natureza como um processo que não apenas trouxe à tona a nós humanos como seres naturais, mas também que ela continua ativa através de nós. Foi com Schelling que Bloch se apercebeu da tarefa da filosofia da natureza que consiste em compreender a natureza a partir de suas próprias potências, de modo que se 
torne visível como ela se organiza a si mesma desde si mesma, desde a 'matéria processual', perpassando pelos organismos vivos até a consciência humana. Nisso a totalidade do processo da natureza, como existência e devir criador, de modo algum está conclusa, abrigando ainda em si - e por fim também em nós - possibilidades, que lhe emprestam um horizonte de futuro aberto.

E essas cifras reais existem justamente porque o próprio processo do mundo é uma função utópica, tendo a matéria do objetivamente possível como substância. Neste contexto, a função utópica do planejamento e da transformação humanamente consciente representa apenas o posto mais avançado, mais ativo da função auroral que ronda o mundo: do dia noturno em que todas as cifras reais, isto é, todas as formas processuais ainda estão em andamento e se encontram (Bloch, 2005, p. 176).

Aqui se pode perceber - e igualmente contra a tendência de compreensão dominante de técnica - o motivo pelo qual Bloch dirige, especialmente no capítulo sobre 'Vontade e natureza' no Princípio Esperança, seu esperançar e antecipar de forma concreta e utópica em direção a uma técnica da aliança com a natureza, pois a técnica não deve ser compreendida e abusada equivocadamente como sendo uma intervenção arbitrária na natureza, porque ela retira sua força da dominação consciente das forças da natureza. Por isso precisamos compreender a técnica desde as potências da natureza e, assim, aprender a avançar com elas (cf. SchmiedKowarzik, 2020a).

\footnotetext{
Na realidade, porém, [a natureza] nem acabou de florescer nem a história humana com sua corporeidade, seu contexto e sobretudo com sua técnica, está ligada à natureza somente como algo passado. Pelo contrário: a natureza definitivamente manifesta não se situa diferentemente da história definitivamente manifesta no horizonte do futuro, e somente neste convergem também as futuramente bem expectáveis categorias de mediação da técnica concreta. Quanto mais precisamente se tornar viável uma técnica da aliança em lugar da externa, uma mediada com a coprodutividade da natureza, tanto mais seguramente as forças construtivas de uma natureza congelada voltam a ser liberadas (Bloch, 2006, p. 244).
}

c) Se trata agora de migrar da filosofia da natureza enquanto processo para a filosofia da história da emancipação. Sem dúvida, essa linha de pensamento filosófica, em favor da qual Bloch se confessa decididamente, é de ser pensada na sucessão de Karl Marx. É nela que Bloch, sem titubear, define a si mesmo como marxista. Mesmo assim é espantoso o quão pouco Bloch, em seus trabalhos histórico-filosóficos, se atém à proposta marxiana de compreender a história humana desde a produção social e suas formas de alienação; isso é ainda mais espantoso pelo fato de que a história da produtividade humana, mesmo que não

\begin{tabular}{|l|l|l|l|l|}
\hline Q Qonista Dialectus & Ano 10 & n. 21 & Janeiro - Abril 2021 & p. $271-295$ \\
\hline
\end{tabular}


linearmente, mas sim dialeticamente, representaria justamente uma parte que estaria necessariamente em conexão com a filosofia da Bloch.

É claro que Bloch recorre ao legado de Marx pelo fato de ter demonstrado a "força do poder dos processos de produção [...], a verdadeira mola propulsora da história até o presente", mas ele não se entretém por muito tempo com esse trabalho já realizado por Marx e se volta - numa virada política, para Hegel - para a história como realização consciente da liberdade. E aqui merecem ser mencionados os dois trabalhos - Liberdade e ordem (1949, que mais tarde foi incorporado ao Princípio Esperança) e Direito natural e dignidade humana -, nos quais persegue a discussão política fundamental em torno das utopias sociais e dos direitos humanos através da tradição europeia, sem nunca perder de vista uma socialismo libertário, como sendo o objetivo utópico concreto:

Daí a herança própria do direito natural revolucionário anterior: superação de todas as relações onde o ser humano, juntamente com as coisas, foi alienadamente degradado à mercadoria, e não apenas à mercadoria, mas à nulidade em termos de valor próprio. Nenhuma democracia sem socialismo, nenhum socialismo sem democracia, essa é fórmula de uma interação recíproca, que decide sobre o futuro (Bloch, 1977e, p. 232).

Concretamente mais político Bloch se torna na sua análise temporal dos anos de

Weimar e do surgimento do nacional-socialismo em Herança dessa época. Também a sua dialética da não simultaneidade de acontecimentos e movimentos históricos, mesmo que pertencentes a uma mesma época, conta entre os enriquecimentos fundamentais no interior da discussão marxista. Em seu conjunto, no entanto, a referência de Bloch a Marx permanece confessional e apelativa - como, por exemplo, no grande acorde final chamado "Karl Marx e o espírito humanitário"9 no Princípio Esperança:

\footnotetext{
Portanto, essa alienação, desumanização, reificação, esse devir-mercadoria do todos os seres humanos e todas as coisas, na forma como o capitalismo o produziu em grau crescente: esse é, para Marx, o velho inimigo, que acabou triunfando como nunca no capitalismo, como capitalismo. O próprio espírito humanitário é o inimigo nato da desumanização; sim, do fato de o marxismo nada mais ser que a luta contra a desumanização que culmina no capitalismo até sua completa anulação, resulta também e contrário que o marxismo autêntico, de acordo com sua motivação, sua luta de classes e seu teor final, nada é, nada pode ser e nada será além de promoção do espírito humanitário (Bloch, 2006a, p. 444).
}

9 Com a tradução de Menschlichkeit por “espírito humanitário" parece se perder um pouco do caráter combativo do termo (contrário a Entmenschlichung: traduzido na passagem citada, adequadamente, por desumanização). Talvez fosse melhor traduzir por "Karl Marx e o humanitarismo", já que humanismo também não conferiria, uma vez que existe o conceito alemão de Humanismus, preterido por Bloch nessa passagem. (Nota do Tradutor) 
d) A terceira temática central (Themmenschwerpunkt), que é a estética, é a que ocupa, desde Espírito da utopia, o maior espaço na obra de Bloch. Já em Espírito da utopia as questões relacionadas ao encontro consigo mesmo nas artes plásticas e na música, ao lado das questões filosóficas, estão em primeiro plano e, da mesma forma, na obra principal Princípio Esperança. Juntamente com outros tratados artístico-teóricos espalhados, esses estudos artístico-filosóficos foram reunidos nos dois volumes da Estética do pré-aparecer [Ästhetik des Vorscheins]. A isso se juntam alguns textos literários de Bloch, como os livros Vestígios [Spuren] e Estranhamentos [Verfremdungen]. Neles arte e literatura se fundem enquanto meios e objetos em produtividade criativa e, simultaneamente, fazem transparecer diretamente o 'indicar para adiante' do pensamento de Bloch. Como eu já abordei a obra literária de Bloch nas considerações iniciais, gostaria de, aqui neste esboço resumido, abordar logo o quarto e último dos principais problemas filosóficos-reais, que é a escatologia.

e) Para Bloch, a escatologia ou o apocalipse positivamente compreendido é - como já indicado no Espírito da utopia - o último horizonte-alvo, aquilo que direciona positivamente rumo ao porvir do reino, aquilo que pulsa e pressiona em nós e no mundo. Esse horizonte-alvo é também o que empresta a forte coragem e a esperança acalentadora às irrupções revolucionárias, como Bloch pôde demonstrar especialmente no livro Thomas Münzer, teólogo da revolução, no caso das guerras camponesas com suas raízes subterrâneas e suas consequências.

Os trabalhos sobre o escatológico estão ao lado daquilo que Bloch expôs em sua filosofia do processo natural e têm seu auge no livro Ateísmo no cristianismo. Trata-se de um novum dos mais empolgantes que ele introduziu na discussão filosófica e que o torna independentemente de como nos posicionamos em relação às suas exposições - um dos maiores pensadores do século 20. Ateísmo no cristianismo é a tentativa de compreender a tradição de fé judaico-cristã a contrapelo das solidificações igrejeiras a fim de direcioná-las para irrupções de esperanças rebeldes. Bloch busca entender a Bíblia não como um livro revelado por Deus, mas sim, ateisticamente, como um livro do horizonte humano-escatológico. Todo o ateísmo até aqui repousa sobre reducionismo e proibição de pensamento, motivo pelo qual o reprimido irrompe em outros lugares na forma de visões de mundo pseudorreligiosas e em estruturas grotescas e, muitas vezes, doentes - o nacional-socialismo e o stalinismo carregam desses traços. Na medida em que Bloch, para além daquilo que havia sido iniciado em Feuerbach, herda as tradições religiosas a partir de seus conteúdos de sentido, seu "ateísmo religioso" entra em um diálogo livre e numa interação produtiva com todas as forças humanistas das comunidades judaicas e

\begin{tabular}{|c|c|c|c|c|}
\hline Qevista Dialectus & Ano 10 & n. 21 & Janeiro - Abril 2021 & p. $271-295$ \\
\hline
\end{tabular}


cristãs - para o desafio produtivo da nossa procura por nós mesmos e por sentido no horizonte escatológico (cf. Schmied-Kowarzik, 1998).

\begin{abstract}
[...] Não existiria um humanismo sustentável se, para além de sua moral, ele não implicasse sobremaneira também essas felizes imagens-limite do 'para onde' e do 'para quê'. Também a liberdade dessas se encontra no prolongamento do homo absconditus que ainda não veio à tona no mundo, no experimento do mundo. Liquidação do humano já temos o suficiente [...]. E mesmo assim, todo o mundo de puros fatos [...] não é verdadeiro. Verdadeiro é somente o processo nele contido, incluída a voz do rebelde que, com uma posição bem diferente, pertencendo partidariamente ao novum, pôde dizer a Pilatos: 'Quem está fora da verdade escuta a minha voz'. Seu lugar é a luta, a diferenciação, a corrente quente e, consequentemente, a reputação humana e sua inserção no front do processo-mundo. [...] Se a emancipação dos sobrecarregados e esgotados ainda é pretendida pelos cristãos, se para os marxistas o reino da liberdade permanece e se faz o conteúdo substancial da consciência revolucionária, então, a aliança entre revolução e cristianismos nas guerras camponesas não há de ter sido a última - dessa vez com sucesso. [...] Vivat sequentes; assim se unem, então, no mesmo caminho e no plano de combate, o marxismo e o sonho do incondicionado. O humano não mais alienado, o suspeitado, porém ainda não encontrado de seu mundo possível, ambos estão incondicionalmente situados no experimento do futuro, experimento-mundo (Bloch, 1977, p. 352-354).
\end{abstract}

\title{
IV. Observações críticas
}

Ernst Bloch é um pensador visionário, um apologeta positivo das imagens de esperança e das fundações de sentido. Como, no entanto, não argumenta de modo conceitualmente fundamentado nem demonstrativamente, tudo o que é por ele exposto sucumbe facilmente à crítica. Isso evidentemente não quer dizer que a crítica destrutiva tenha razão, mas, chama atenção para a vulnerabilidade desse filosofar - um filosofar que vive da intuição de ideias (Denk-Einfall), as quais apenas transcreve, transfigura, revira e, nos momentos apologéticos ou polêmicos, culminam em confissões com palavras fortes e alegações.

Por outro lado, no entanto, desde Bloch facilmente se deixa abrir uma contraconta (Gegenrechnung), pois nem no movimento conceitual da lógica nem no deserto gelado da abstração ocorrem as visões exaustivamente presentes no momento obscuro do agora que nós mesmos somos e, por isso, estão vivas em todos nós, e em direção às quais Bloch avança. Aqui se mostra, para mim, que nós precisamos de ambos em mediação dialética: o esperançar positivo de Bloch e algo como uma dialética negativa. Somente os dois juntos nos levarão adiante.

Aqui um exemplo: Bloch, na realidade, nunca se aproximou muito do projeto marxiano da Crítica da economia política e nunca acompanhou a reivindicação aí implícita de uma teoria crítico-negativa da violência negativa. Desde sua teoria das esperanças positivas ele nem mesmo reconhece a necessidade de dar continuidade a tal teoria, uma teoria que se volta

\begin{tabular}{|l|l|l|l|l|}
\hline Qovista Dialectus & Ano 10 & n. 21 & Janeiro - Abril 2021 & p. 271 - 295 \\
\hline
\end{tabular}


contra aqueles poderes que inviabilizam as condições de possibilidade de realização da esperança. De onde ele retira a certeza de que o socialismo e a técnica da aliança virão? Nada disso virá se nós abandonarmos o processo histórico a si mesmo, ou seja, aos ditames da economia capitalista do valor. Evidenciar isso criticamente em uma teoria negativa da lógica negativa das forças dominantes, a fim de indicar os caminhos da superação revolucionária para a práxis, foi o projeto de Marx, o qual, inclusive, nós hoje estamos desafiados a expandir para a problemática ecológica.

Há muito o problema do apocalipse se tornou diferente daquele de 70 anos atrás. O fim do mundo será obra do próprio ser humano se nós não formos capazes de nos conduzir pelos nossos próprios braços (cf. Sonnemann, 1969). Ernst Bloch também intuiu isso em seus últimos trabalhos e adverte de modo impressionante:

\begin{abstract}
A autêntica teoria-práxis retira metodicamente os objetivos para a ação da análise daquele entorno a ser transformado, e o socialismo como fim último é a conditio sine qua non dessa práxis. Uma tal práxis não pode se limitar a libertar da alienação as relações dos seres humanos com os seres humanos rumo a uma sociedade sem classes; ela avança transformando também a relação dos seres humanos com a natureza. De forma que o ser humano não precise mais estar na natureza como se estivesse em território inimigo, com a ameaça permanente dos acidentes técnicos. [...] Uma relação diferenciada, não mais exploradora com a natureza já foi significada, conforme possibilidades real-objetivas, enquanto uma técnica da aliança concreta e amigável. [...] Isso se torna ainda mais necessário quando se tem em conta que o acidente há muito passou a ter o significado de um ameaçador autoextermínio da humanidade: destruição minuciosa de suas condições existenciais naturais por meio do desprezo da ecologia (Bloch, 1977b, p. 251).
\end{abstract}

Palavras bonita e assertivas, mas somente palavras, se não vierem acompanhadas de uma crítica à ciência natural e à técnica sob a tutela da economia do valor, que nomine concretamente o perigo ameaçador e, com isso, os necessários contrapassos. Uma tal crítica falta em Bloch, em todas as partes do seu sistema.

Porém, eu não quero ser mal entendido: à crítica, por outro lado, geralmente falta a abertura positiva de sentido, e que é justamente pelo que Bloch pergunta instigante e insistentemente em sua obra. Sem ela não podemos perceber por que e com que objetivos, afinal de contas, nós havemos de lutar.

Por isso Bloch é, para mim, um dos grandes inauguradores de problemas (Problemeröffner) filosóficos. A nós cabe continuar desenvolvendo criticamente esses horizontes de questões por ele abertos.

\begin{tabular}{|l|l|l|l|l|}
\hline Qovista Dialectus & Ano 10 & n. 21 & Janeiro - Abril 2021 & p. $271-295$ \\
\hline
\end{tabular}




\section{Referências}

BLOCH, Ernst. Atheismus im Christentum. Zur Religion des Exodus und des Reichs. Gesamtausgabe 14. Frankfurt a. M.: Suhrkamp, 1977.

BLOCH, Ernst. Espírito da utopia. Tradução de Oliver Tolle. São Paulo: Editora 34, no prelo, S/D.

BLOCH, Ernst. Erbschaft dieser Zeit. Gesamtausgabe 04. Frankfurt a. M.: Suhrkamp,1977a.

BLOCH, Ernst. Experimentum mundi. Fragen, Kategorien des Herausbringens, Praxis. Gesamtausgabe 15. Frankfurt a. M.: Suhrkamp, 1977 b.

BLOCH, Ernst. Geist der Utopie. Erste Fassung. Gesamtausgabe 16. Frankfurt a. M.: Suhrkamp, 1977c.

BLOCH, Ernst. Geist der Utopie. Zweite Fassung. Gesamtausgabe 03. Frankfurt a. M.: Suhrkamp, 1977d

BLOCH, Ernst. Naturrecht und menschliche Würde. Gesamtausgabe 06. Frankfurt a. M.: Suhrkamp, 1977e.

BLOCH, Ernst. O Princípio Esperança, Vol. I. Tradução de Nélio Schneider. Rio de Janeiro: EdUERJ: Contraponto, 2005.

BLOCH, Ernst. O Princípio Esperança. Vol. II. Tradução de Werner Fuchs. Rio de Janeiro: EDUERJ: Contraponto, 2006.

BLOCH, Ernst. O Princípio Esperança, Vol. III. Tradução de Nélio Schneider. Rio de Janeiro: EdUERJ: Contraponto, 2006a.

BLOCH, Ernst. Spuren. Gesamtausgabe 01. Frankfurt a. M.: Suhrkamp, 1977f.

BLOCH, Ernst. Thomas Münzer als Theologe der Revolution. Gesamtausgabe 02. Frankfurt a. M.: Suhrkamp,1977g.

BLOCH, Ernst. Thomas Münzer, teólogo da revolução. Rio de Janeiro: Biblioteca Tempo Universitário, 1973.

BLOCH, Ernst. Tendenz - Latenz - Utopie. Ergänzungsband zur Gesamtausgabe. Suhrkamp: Frankfurt a. M. , 1985.

FISCHER, Franz. Proflexion - Logik der Menschlichkeit. Späte Schriften und letzte Entwürfe, 1960 - 1970. Hrsg. v. Michael Benedikt u. Wolfgang W. Priglinger. München: Löcker Verlag, 1985.

SCHELLING, Friedrich Joseph. Philosophie der Offenbarung. In: Sämtliche Werke. Band II/03. Stuttgart; Augsburg: J.G. Cotta'scher, 1958.

\begin{tabular}{|c|c|c|c|c|}
\hline Qovista Dialectus & Ano 10 & n. 21 & Janeiro - Abril 2021 & p. $271-295$ \\
\hline
\end{tabular}


SCHMIED-KOWARZIK, Wolfdietrich. A relação dialética do homem com a natureza. Estudos histórico-filosóficos sobre o problema da natureza em Karl Marx. Tradução de Rosalvo Schütz. Cascavel: Edunioeste, 2019.

SCHMIED-KOWARZIK, Wolfdietrich. Ernst Bloch: esperança por uma aliança entre história e natureza. Tradução de Rosalvo Schütz. In: Revista Veritas. Porto Alegre, v. 64 (3) e34619, 2019a. https://doi.org/10.15448/1984-6746.2019.3.34619.

SCHMIED-KOWARZIK, Wolfdietrich. "Weit hinaus zu hoffen". Kritisches zu Blochs humanen Atheismus. In: Jahrbuch der Ernst-Bloch-Gesellschaft, 1998.

SCHMIED-KOWARZIK, Wolfdietrich. Wider Barbarei und Apokalypse. In: SCHMIEDKOWARZIK, Wolfdietrich. Bildung, Emanzipation uns Sittlichkeit. Philosophiesche und pädagogische Klärungsvesuche. Weinheim: Deutscher Studien Verlag, 1993.

ULRICH, Sonnemann. Negative Antropologie. Vorstudien zur Sabotage des Schicksals. Reinbek b. Hamburg: Rowohlt, 1969.

\begin{tabular}{|c|c|c|c|c|}
\hline Qovista Dialectus & Ano 10 & n. 21 & Janeiro - Abril 2021 & p. $271-295$ \\
\hline
\end{tabular}

